\title{
Mechanical performance study of the retractable pier column after stiffening
}

\author{
Yi Zhang ${ }^{1} \cdot$ Xiaoye Wang ${ }^{1} \cdot$ Liming Zhao $^{1}$ (i) $\cdot$ Jie Liu $^{1} \cdot$ Nana Wang $^{1} \cdot$ \\ Yingying Ding ${ }^{1}$
}

Received: 7 October 2019/Revised: 17 April 2020/Accepted: 5 July 2020/Published online: 4 August 2020

(C) The Author(s) 2020

\begin{abstract}
To solve the problem that the overlapping parts of a retractable pier column are prone to damage, this paper proposed the reinforcing measure of setting a stiffener ring at the bottom of the steel pipe. To study how the stiffener-ring parameters influence the mechanical properties of the pier column, 12 scale model specimens (including nine specimens with stiffener-ring widths of 40,50, and $60 \mathrm{~mm}$ and three unstiffened comparison specimens) were tested under axial compression. Based on the test results, the specimen load-displacement, load-deflection, and load-strain curves were analyzed, and a finite-element model of a pier column under axial compression was established to determine the optimal stiffener size. The results show that setting a stiffener ring enhances the cooperative working ability between the steel pipe and the internal filling material and restrains the lateral deformation of the pier column, thereby improving the ultimate bearing capacity and overall stability of the pier column. The ultimate bearing capacity of the pier column is related to the width and thickness of the stiffener ring. The optimal size of the stiffener ring of the model pier column is $70 \mathrm{~mm}$ in width and $4 \mathrm{~mm}$ in thickness. The present research results provide a reference for designing compressible pier columns and column stiffening in mines and have important practical significance.
\end{abstract}

Keywords Retractable pier column · Stiffening reinforcing · Axial compression test · Ultimate bearing capacity $\cdot$ Finiteelement analysis

\section{Introduction}

Retractable adaptive pier columns offer a new way to support a roadway. The filler material used is compressible and can be adapted to a given deformation caused by the overall subsidence of the overburden (Qian et al. 2003; Jia et al. 2014; Guo et al. 2018; Jack et al. 2019). The advantages are simple manufacturing technology, low economic cost, and high early support strength at the support site. Moreover, the rapidly increasing resistance offers good lane retention (Wang et al. 2015; Li et al. 2015; He et al. 2017; Ju et al. 2019). However, since the pier

Liming Zhao

Zlmcumtb@163.com

1 School of Mechanics and Architecture Engineering, China University of Mining and Technology, Beijing 100083, China column is made of two nested steel tubes, it is relatively long and thick. Under the continuous roof load, the central lap position of the pier column is prone to bending failure due to eccentric pressure, as shown in Fig. 1. Local instability of the pier column leads to insufficient bearing capacity, and the shrink quantity cannot meet the pressure relief requirements. Therefore, it is necessary to improve and reinforce the vulnerable points of the structure.

To date, there has been much beneficial research on the strengthening of concrete-filled steel tube (CFST) structures. To improve the structural bearing capacity, Dong et al. proposed using steel tubes filled with concrete reinforced by carbon-fiber-reinforced polymer (CFRP) (Dong et al. 2013; Ganesh and Sundarraja 2013; Park and Choi 2013). They analyzed the structural composition and mechanical mechanism theoretically, and a comparative test of the bearing capacity showed its superiority. Li et al. (2012) and Hassanein et al. (2013) proposed a 


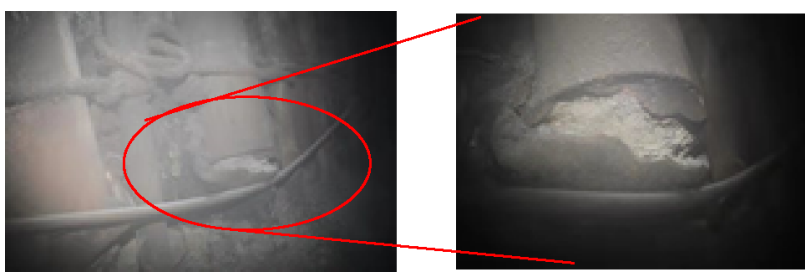

Fig. 1 Characteristics of pier column failure on site

strengthening measure of outer bread steel pipe to enhance the bearing capacity of a CFST. Referring to the common reinforcement methods of CFST columns, such as pasting CFRP, outer bread steel pipe method, enlarged section strengthening method and so on, CFRP has high tensile strength and favorable fatigue resistance, but its disadvantages include anisotropy, poor shear strength, and high price. External steel reinforcement is more suitable for shorter CFST columns, but the construction process is complex.

In this paper, a stiffener ring (SR) is set up in the plastic hinge area in the middle of the pier column, and an axial compression test is carried out. Comparing the failure modes of the pier column before and after stiffening shows how the mechanical properties of the pier column change after stiffening. Finally, finite-element (FE) analysis is used to optimize the parameters of the stiffener and select the optimal stiffener size suitable for the pier column. This method is simple in operation, flexible in strengthening position, and low in cost, thereby helping to minimize pipe buckling and increase the overall stability. Furthermore, it provides a reference for the stiffening design of collapsible pier columns for mines, which should help to further the popularity and applicability of collapsible pier columns.

\section{Experiment}

\subsection{Analysis of stiffening form and reinforcing mechanism of pier column}

As a pier column is essentially a CFST, when it bears an axial load, the steel tube provides transverse constraint for the internal filling material so that the latter is in a state of three-way stress, thereby improving its bearing capacity. Meanwhile, as the internal filling material is compressed and expands, the steel pipe is subjected to the reaction of the radial stress of the internal filling material while providing constraints, thereby limiting its own deformation and delaying buckling. The steel pipe of the pier column is composed of two nested steel pipes. The outer radius of the upper steel tube is $\varphi 351 \mathrm{~mm} \times 8 \mathrm{~mm}$, and the inside radiu is $339 \mathrm{~mm}$; the outer radius of the lower steel tube is $\varphi 325 \mathrm{~mm} \times 8 \mathrm{~mm}$, and the inside radius is $309 \mathrm{~mm}$.
Thus, the steel tube can be regarded as a thin-walled cylinder (Guo et al. 2013a, b). The section of which is shown in Fig. 2. From the formula for calculating the stress of a thin-walled cylinder, we have

$$
\begin{aligned}
& \sigma_{r}=\frac{a^{2}}{b^{2}-a^{2}}\left(1-\frac{b^{2}}{r^{2}}\right) p_{\mathrm{i}}-\frac{b^{2}}{b^{2}-a^{2}}\left(1-\frac{a^{2}}{r^{2}}\right) p_{0} \\
& \sigma_{\theta}=\frac{a^{2}}{b^{2}-a^{2}}\left(1+\frac{b^{2}}{r^{2}}\right) p_{\mathrm{i}}-\frac{b^{2}}{b^{2}-a^{2}}\left(1+\frac{a^{2}}{r^{2}}\right) p_{0}
\end{aligned}
$$

where $a$ is the inner radius, $b$ is the outer radius, $r$ $(a<r<b)$ is any radius, $p_{\mathrm{i}}$ is the internal pressure, $p_{0}$ is the external pressure, and $t$ is the thickness of the steel tube.

$\sigma_{\theta \max }=\sigma_{\theta r-a}=\frac{b^{2}+a^{2}}{b^{2}-a^{2}} p_{\mathrm{i}}$

where $p_{\mathrm{i}}$ is the internal pressure, $p_{\mathrm{i}}=k q=(1-\sin \theta) q$, where $k$ is the coefficient of lateral pressure $(k=1-\sin \theta)$

$\sigma_{\theta \max }=\frac{b^{2}+a^{2}}{b^{2}-a^{2}}(1-\sin \theta) q=f_{y}$

$q=\frac{f_{y}\left(b^{2}-a^{2}\right)}{b^{2}+a^{2}} \cdot \frac{1}{1-\sin \theta}=\frac{f_{y}(b+a) t}{b^{2}+a^{2}} \cdot \frac{1}{1-\sin \theta}$

According to Eq. (5), when the inner radius of the steel pipe is fixed, the ultimate bearing capacity of the thinwalled cylinder can be improved by increasing its outer radius, which means adding lateral constraints to the outer wall of the steel pipe. When local buckling or expansion occurs, the reserved additional lateral constraints and the gap between the steel tubes are gradually eliminated. At this time, the existence of additional transverse constraints subjects the steel pipe to its radial stress, thereby putting the internal filling material into a more effective three-way stress state and improving the mechanical performance of the steel pipe and the internal filling material. At the same time, by setting additional transverse constraints, the section stiffness of the steel pipe in the restrained part changes before and after buckling, thereby improving the plastic deformation capacity of the specimen, delaying the buckling failure of the steel pipe, and improving the ultimate bearing capacity of the specimen (Xiao and $\mathrm{He} 2003$ ). Figure 3 shows the stress state of the specimen, from which it can be seen that the additional constraints have no effect

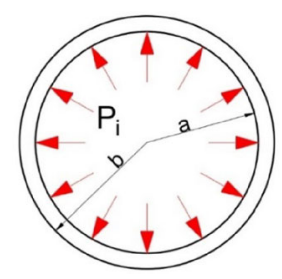

Fig. 2 Schematic of sections of steel pipe 

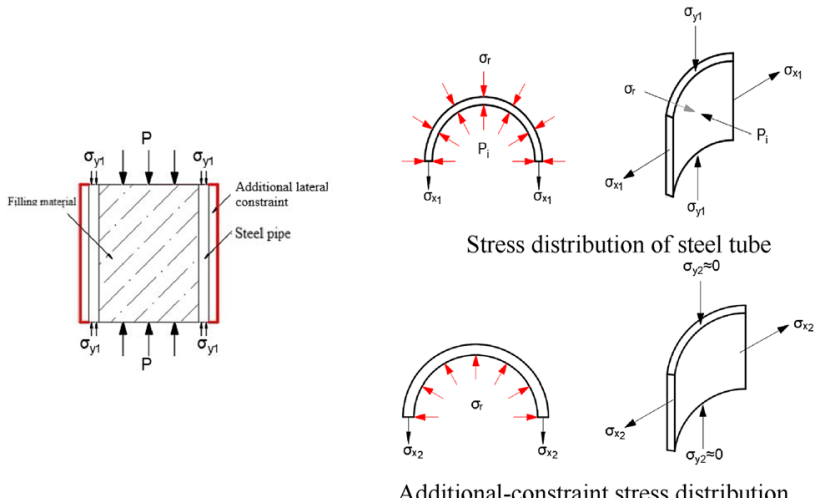

Fig. 3 Additional lateral restraint mechanism of pier column

on the deformation of the steel tube before it bends. As long as the reserved void disappears because of the buckling deformation of the steel pipe, the additional constraints will come into play, thereby limiting the transverse deformation of the steel pipe. Because the additional constraint is only applied to the middle of the specimen and the lower section is on the free face, the vertical load cannot be transferred. Therefore, the additional constraint is in the state of bidirectional stress, that is, it bears the circumferential stress while receiving the radial compressive stress transferred from the steel pipe. The stress state in both directions is similar to that of the steel pipe.

Referring to the common reinforcement methods for existing long CFST columns, an effective way to avoid premature local buckling of the steel tube is to increase the lateral additional constraint of the CFST column and improve the flexural and compressive strength of the steel tube by locally setting a stiffening steel casing on the outside of the steel tube (Xiao and He 2003). Therefore, in view of the buckling failure of the steel pipe at the piercolumn lap joint, combined with the construction convenience and cost saving, the present paper proposes the reinforcement measure of setting an SR in the plastic hinge area in the middle of the pier column. The size of the SR can be determined by referring to the strengthening provisions of the axial force members in the technical specification for steel structure reinforcement (Guo et al. 2013a, b). To meet the requirements of the net cross-sectional area of the members after reinforcement, the length of the SR is $150 \mathrm{~mm}$ and the thickness of the steel pipe wall is $8 \mathrm{~mm}$.

\subsection{Test plan design}

The test is designed using a similarity model. The type of pier column used in the Wutongzhuang Mine in Hebei Province, China is taken as the prototype structure. The scale reduction ratio is approximately $1: 3$ and the total height of the model is designed to be $1.2 \mathrm{~m}$. The size parameters of the prototype pier column and test model are given in Table 1. The SR is set on the outer surface of the steel pipe on the pier column. The size of the SR refers to the technical specification for steel structure reinforcement (GB 50017-2003 2003), which determines the length as $150 \mathrm{~mm}$ and the thickness of the steel tube wall as $8 \mathrm{~mm}$. The axial compressive properties of unstiffened and stiffened pier specimens are tested and studied. The width of the SR is set as 40,50 , or $60 \mathrm{~mm}$, and three parallel tests are conducted on the pier specimens of the same size, making a total of 12 groups. The specific stiffening is shown schematically in Fig. 4, and the sample numbers are given in Table 2 .

\subsection{Specimen design and production}

The steel pipe of the pier column is composed of two nested steel pipes. The upper and lower steel tubes are overlapped and the length of the upper and lower steel tubes is $700 \mathrm{~mm}$, and the length of the overlapped part is $200 \mathrm{~mm}$. The wall thickness of the steel pipe is $3 \mathrm{~mm}$. The reinforcing ring and the steel pipe are fixed at the lower end of the upper steel pipe by means of interval spot welding. The steel tube specimens after lapping is shown in Fig. 5.

Regarding the specimen pouring and curing, the filling material is placed on a vibrator to vibrate it fully. When filling, the upper pier column is fixed with a bracket, and a vibrating rod with a diameter of $3 \mathrm{~cm}$ is used to vibrate it fully. The specimen is maintained at room temperature for $14 \mathrm{~d}$.

\subsection{Test equipment and loading system}

The test loading device is a YAJ servo hydraulic press produced by Zhubang Co., Ltd., with a maximum load of $1000 \mathrm{kN}$ and a maximum loading displacement of $100 \mathrm{~mm}$. The test device is shown schematically in Fig. 6 and physically in Fig. 7. The whole test process is conducted by the electro-hydraulic servo test system, and the test stress-strain data are collected in real time by the static strain data acquisition system on the computer. The specific parameters of the strain gauges are given in Table 3.

The loading method of this test adopts the combination of displacement control and force control. Before loading, a force load of $5 \mathrm{kN}$ is preloaded on the specimen. Within the elastic range, force loading method is adopted and the loading speed is $0.05 \mathrm{kN} / \mathrm{s}$. When the loading curve bends, the displacement loading mode is adopted, and the loading speed is $0.01 \mathrm{~mm} / \mathrm{s}$. When the loading curve shows a gentle trend, the displacement loading speed is adjusted to $0.008 \mathrm{~mm} / \mathrm{s}$, and the number of data collected is increased. 
Table 1 Dimensions of original structure and model

\begin{tabular}{|c|c|c|c|c|c|c|c|c|c|}
\hline \multirow[t]{2}{*}{ Category } & \multicolumn{3}{|c|}{ Upper steel tube (mm) } & \multicolumn{5}{|c|}{ Lower steel tube (mm) } & \multirow{2}{*}{$\begin{array}{l}\text { Lap length (mm) } \\
H\end{array}$} \\
\hline & $D_{1}$ & $d_{1}$ & $I_{1}$ & $t_{1}$ & $D_{2}$ & $d_{2}$ & $I_{2}$ & $t_{2}$ & \\
\hline Prototype pier & 351 & 335 & 2000 & 8 & 325 & 309 & 2000 & 8 & 600 \\
\hline Model of specimen & 121 & 115 & 700 & 3 & 114 & 108 & 700 & 3 & 200 \\
\hline
\end{tabular}

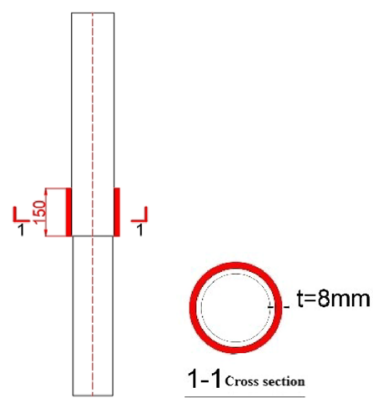

Fig. 4 Schematic of pier column

The test is terminated when the bearing capacity of the specimen falls below $85 \%$ of the ultimate load.

The data collected by the test include load value applied by the loading machine, displacement value of the displacement meter, strain gauge strain value, etc. The vertical force exerted by the jack on the specimen is measured by the force sensor on the loading head of the servo hydraulic press. The vertical displacement and lateral deflection of the specimen are measured by a displacement meter. Four longitudinal and circumferential resistance strain gauges are affixed at $90^{\circ}$ intervals to the parts on the outer surface of the steel tubes prone to local buckling. The positions and numbers of the displacement gauges are shown in Fig. 8, and the arrangement of the strain gauges is shown in Fig. 9.

\subsection{Material properties}

The test-piece steel pipe is a $3 \mathrm{~mm}$ thick seamless round steel pipe with material quality Q325B. Standard test pieces are selected to conduct a uniaxial tensile test on an electronic universal test machine. The uniaxial tensile test results are given in Table 4 .

The steel pipe is filled with sand, stone, hydrated lime and other materials. The filling quality refers to the mining pier columns. The quality ratio is sand:gravel:hydrated lime: water $=1: 1.6: 0.5: 0.3$. The average quality of each pier-column filling material is given in Table 5 .

The technical requirements for the filling materials are that the sand should be medium sand in zone II, and no less than $15 \%$ of the sand should be able to pass through $0.315 \mathrm{~mm}$ sieve holes. When artificial sand is used, the stone powder content should not exceed 3\%. Gravel is

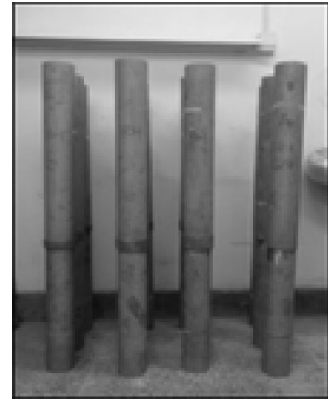

Fig. 5 Lapped steel tube specimens

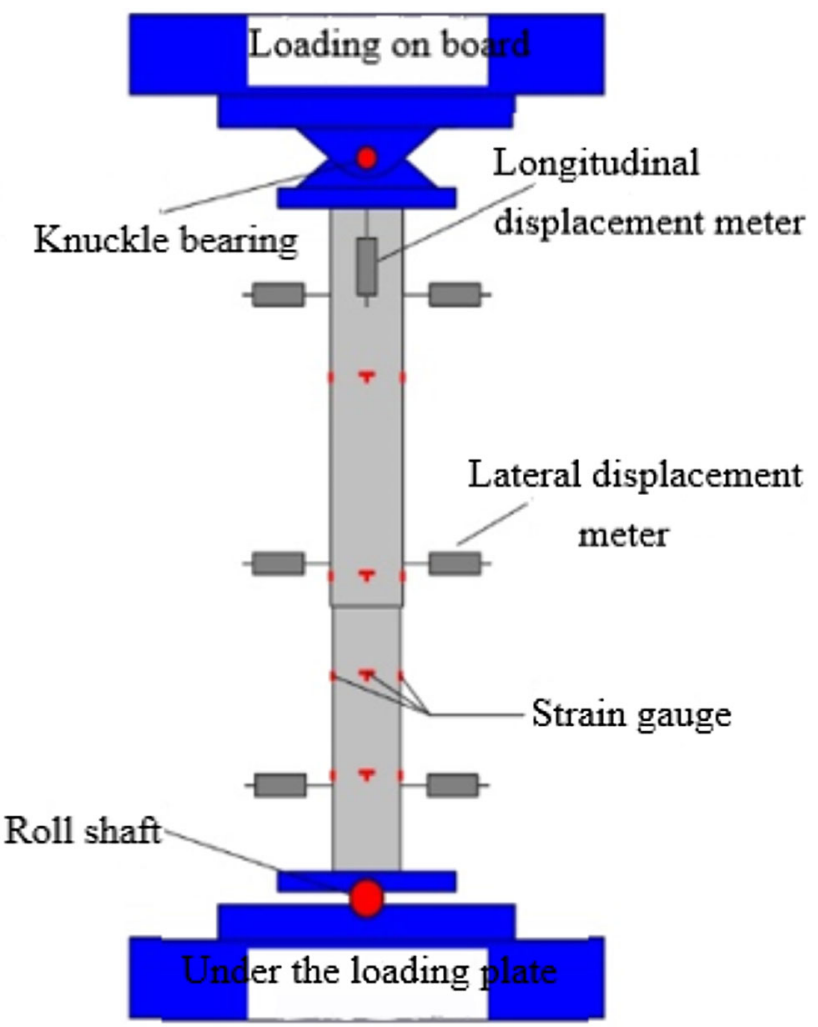

Fig. 6 Schematic of test device

selected with a continuous gradation of $5-16.5 \mathrm{~mm}$. The mud content (by mass) should not exceed 1\%, and the mud content should not exceed $0.5 \%$.

A grading sieve $(5 \mathrm{~mm}, 16.5 \mathrm{~mm})$ is used to sieve the coarse aggregate of the stone as the supporting material. 
Table 2 Specimen numbers and dimensions

\begin{tabular}{|c|c|c|c|c|c|c|c|c|}
\hline \multirow[t]{2}{*}{ Specimen number } & \multicolumn{3}{|c|}{ Upper steel tube (mm) } & \multicolumn{3}{|c|}{ Lower steel tube (mm) } & \multicolumn{2}{|c|}{ Stiffener ring $(\mathrm{mm})$} \\
\hline & $D_{1}$ & $I_{1}$ & $t_{1}$ & $D_{2}$ & $I_{2}$ & $t_{2}$ & $B$ & $t_{3}$ \\
\hline $\mathrm{A} 1, \mathrm{~A} 2, \mathrm{~A} 3$ & 121 & 700 & 3 & 114 & 700 & 3 & - & - \\
\hline $\mathrm{B} 1-1, \mathrm{~B} 1-2, \mathrm{~B} 1-3$ & 121 & 700 & 3 & 114 & 700 & 3 & 40 & 3 \\
\hline $\mathrm{B} 2-1, \mathrm{~B} 2-2, \mathrm{~B} 2-3$ & 121 & 700 & 3 & 114 & 700 & 3 & 50 & 3 \\
\hline B3-1, B3-2, B3-3 & 121 & 700 & 3 & 114 & 700 & 3 & 60 & 3 \\
\hline
\end{tabular}

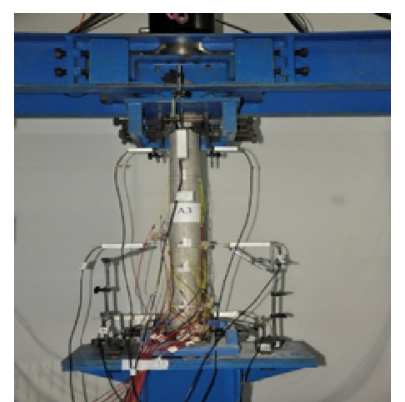

Fig. 7 Photograph of test equipment

Large particles are selected and removed manually so that the proportion of flaky particles in the test material does not exceed $10 \%$. The principle of aggregate screening is based on the maximum diameter of the screening aggregate.

\section{Test phenomenon}

Because the macroscopic phenomena and failure modes of the specimens in each group of parallel tests are similar, only one of the specimens in each group is selected for analysis of the test phenomena.

\subsection{A3: unstiffened specimen}

In the initial loading stage, the vertical displacement of the specimen is large, the upper section of steel pipe has a significant downward displacement, and the specimen has no lateral deformation.

(1) When the load reaches $37.5 \mathrm{kN}$, the load-displacement curve shows a diagonal straight upward trend, and the transverse deformation of the steel pipe is small.

(2) When the load reaches $125 \mathrm{kN}$, the steel pipe begins to yield, especially the upper end of the lower section of steel pipe. There is an obvious lateral deformation, the

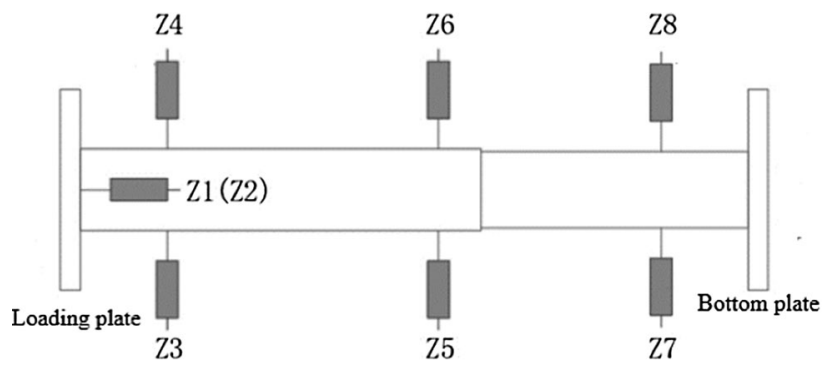

Fig. 8 Layout of displacement meters
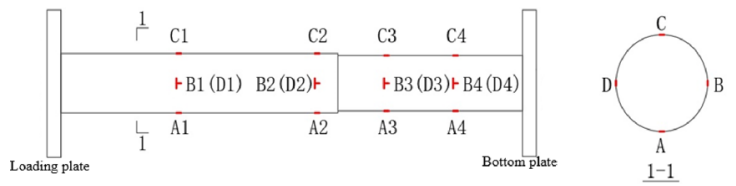

Fig. 9 Arrangement of strain gauges

diameter of the steel pipe becomes thicker. As the loading continues, the overall deformation of the specimen increases, and a large lateral deflection appears at the joints of the steel pipes.

(3) When the load reaches $162.5 \mathrm{kN}$, the vertical displacement of the specimen reaches approximately $31 \mathrm{~mm}$, the load-displacement curve exhibits a descending section, the lateral deflection of the specimen increases sharply, and the upper end of the lower section of steel pipe exhibits an obvious bulge.

(4) When the load drops to around $130 \mathrm{kN}$, the test ends.

\subsection{B1-2: 40-mm-wide stiffener ring}

In the initial loading stage, the specimen is in the compaction stage and the vertical displacement is large.

Table 3 Specifications of strain gauges used in experiment

\begin{tabular}{llllll}
\hline Model & Resistance $(\Omega)$ & Sensitivity coefficient & Product standards & Level & Grid length $\times$ grid width $(\mathrm{mm} \times$ mm) \\
\hline BX120-5 AA & $120 \pm 0.2$ & $2.08 \% \pm 0.5 \%$ & GB/T13992-2010 & A & $5 \times 3$ \\
\hline
\end{tabular}


Table 4 Mechanical properties of steel

\begin{tabular}{llllll}
\hline Item & $\begin{array}{l}\text { Thickness } \\
(\mathrm{mm})\end{array}$ & $\begin{array}{l}\text { Yield strength } \sigma_{\mathrm{s}} \\
(\mathrm{MPa})\end{array}$ & $\begin{array}{l}\text { Tensile strength } \sigma_{\mathrm{b}} \\
(\mathrm{MPa})\end{array}$ & $\begin{array}{l}\text { Elastic modulus } E_{\mathrm{s}} \\
\left(10^{5} \mathrm{MPa}\right)\end{array}$ & $\begin{array}{l}\text { Poisson's ratio } \\
\mu\end{array}$ \\
\hline $\begin{array}{c}\text { Steel } \\
\text { plate }\end{array}$ & 3 & 321 & 456 & 2.02 & $\begin{array}{l}\text { Elongation } \\
\delta\end{array}$ \\
\hline
\end{tabular}

Table 5 Quality of pier filling material

\begin{tabular}{lllll}
\hline Filling volume $\left(\mathrm{m}^{3}\right)$ & Sand quality $(\mathrm{kg})$ & Stone quality $(\mathrm{kg})$ & Slaked lime quality $(\mathrm{kg})$ & Water quality $(\mathrm{kg})$ \\
\hline 0.012 & 9.2 & 14.72 & 4.6 & 2.76 \\
\hline
\end{tabular}

(1) When the load reaches $50 \mathrm{kN}$, the sliding of the upper section of steel pipe slows down, and the specimen has no obvious lateral deformation.

(2) When the load reaches $150 \mathrm{kN}$, the diameter of the steel pipe becomes obviously thicker, and the lower section of steel pipe appears to yield. As the loading continues, the deflection of the middle part of the specimen grows.

(3) When the load reaches $182.5 \mathrm{kN}$, the vertical displacement of the specimen reaches approximately $34 \mathrm{~mm}$, the load-displacement curve begins to fall, the bearing capacity of the specimen decreases, the overall structural deformation is large, and the upper end of the lower section of steel pipe has a larger lateral deformation.

(4) When the load drops to around $157.5 \mathrm{kN}$, the test ends.

\subsection{B2-2: 50-mm-wide stiffener ring}

With the application of the load, the specimen enters the compaction stage, the load-displacement curve shows a slowly rising trend, and the appearance of the specimen does not change.

(1) When the load reaches $50 \mathrm{kN}$, the vertical displacement of the specimen slows down. The load-displacement curve shows that the specimen is in the elastic compression stage at this time, and the lateral deformation of the steel pipe is not obvious.

(2) When the load reaches $175 \mathrm{kN}$, the specimen shows lateral bending at the joint of the steel pipes. As loading continues, the diameter of the steel pipe becomes thicker, the lateral deformation of the specimen is obvious, and the load-displacement curve enters the curved segment from the straight-line segment.

(3) When the load reaches $210 \mathrm{kN}$, the vertical displacement of the specimen reaches approximately $38 \mathrm{~mm}$, the yielding of the steel pipe is obvious, the lateral deformation of the specimen increases continuously, and the bearing capacity of the specimen decreases gradually.
(4) When the load drops to around $177.5 \mathrm{kN}$, the test ends.

\subsection{B3-3: 60-mm-wide stiffener ring}

In the initial stage of loading, the vertical displacement of the specimen is large.

(1) When the load reaches $57.5 \mathrm{kN}$, the filling material is compacted, and the specimen enters the elastic compression stage. The lateral deformation is not obvious, and the vertical displacement increases slowly.

(2) When the load reaches $207.5 \mathrm{kN}$, lateral bending occurs at the joint of the specimen, the diameter of the steel pipe gradually becomes larger, local buckling occurs, the vertical displacement of the specimen decreases, but the lateral deformation is obviously increased.

As the lateral deflection of the specimen continues to increase, the buckling of the upper end of the lower section of steel pipe becomes obvious.

(3) When the load reaches $235 \mathrm{kN}$, the specimen reaches the ultimate load, the corresponding ultimate displacement is $44 \mathrm{~mm}$, and the load-displacement curve appears to fall. As the lateral deflection of the specimen increases, the upper end of the lower section of steel pipe yields significantly.

(4) When the load drops to around $190 \mathrm{kN}$, the test ends.

\section{Analysis of test results}

\subsection{Analysis of load-displacement curves}

Figure 10 shows the load-displacement curve of each specimen. Combined with the test phenomena, it can be seen that the curve comprises the compaction phase, the elastic phase, the elastoplastic phase, and the plastic failure phase. The filling material of the pier-column specimen is a three-phase aggregate composed of sand-stone solid 


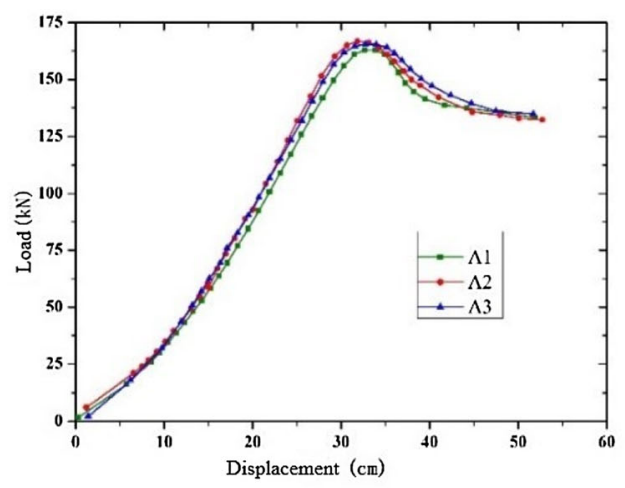

(a) Group-A specimens

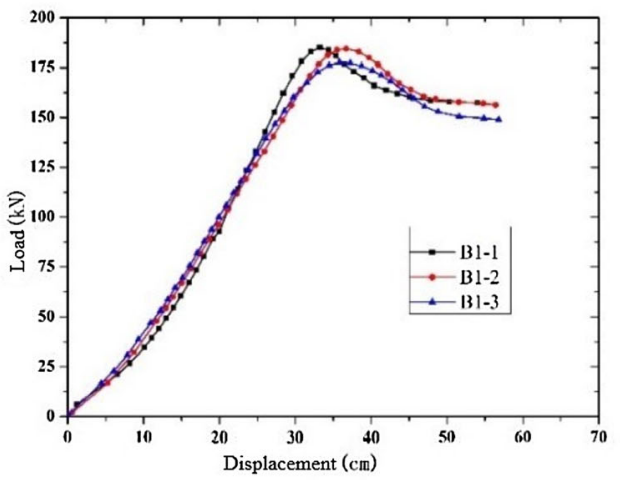

(b) Group-B1 specimens

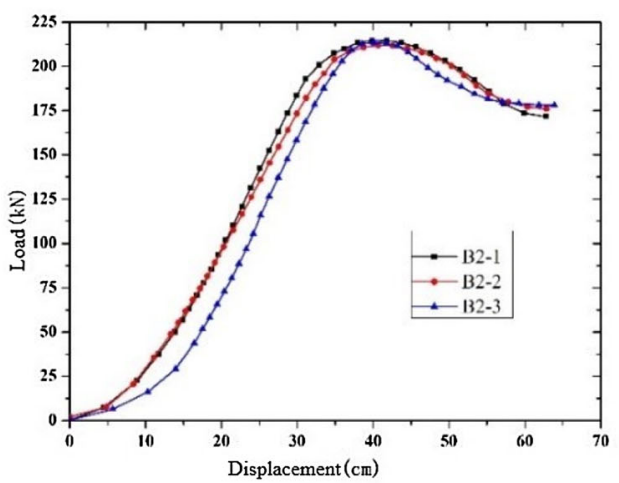

(c) Group-B2 specimens

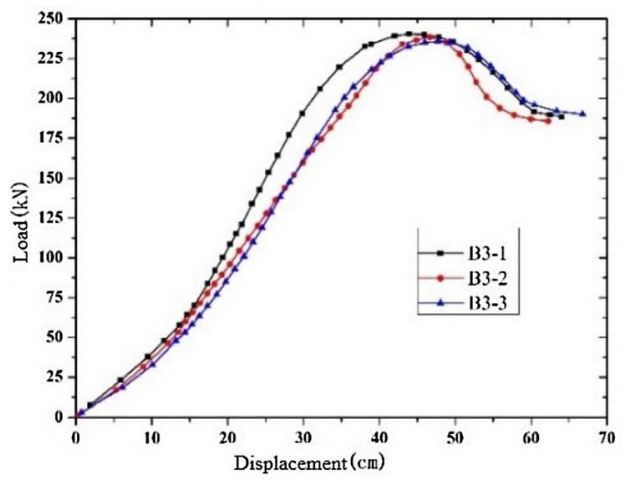

(d) Group-B3 specimens

Fig. 10 Load-displacement curves particles, pore water, and air. The stress generated by the external load in the filling material is transmitted mainly by the mutual contact between the sand and stone particles. This contact stress causes the solid particles of the sand to undergo extrusion deformation, thereby changing the strength of the solid particles of the filler.

In the initial stage of loading, the sand and stone inside the pier column are compressed and compacted, and the water is discharged, showing that the elastic modulus is gradually increasing. At this stage, the upper section of steel pipe is basically not involved in the force, and the load-displacement curve is slowly rising.

In the second stage, the filling material of the pier column has been compressed to a compact state. At this time, the pier column can be regarded as an elastic body obeying Hooke's law, and the load-displacement curve exhibits linear elasticity and shows a straight upward trend.

In the third stage, when the loading reaches around $80 \%$ of the ultimate load, the steel pipe exhibits yield deformation locally, and the load-displacement curve increases in bending, the slope decreases, and the load increase becomes smaller.

In the fourth stage, the stress on the pier column reaches the ultimate strength, the load decreases with the increase of the displacement, and the load-displacement curve enters the descending segment. The sand and stone particles inside the pier are crushed under the joint action of the steel pipe and the axial pressure, the steel-pipe yield deformation is serious, and the bearing capacity of the pier column is reduced until it is destroyed. The setting of the SR increases the lateral restraint ability of the steel pipe to the internal filling material, delays the yield time of the steel pipe, and significantly increases the axial bearing capacity of the pier-column specimen.

\subsection{Analysis of load-deflection curves}

The load-deflection curve reflects the process of instability and failure of the specimen. The lateral deflection $f$ in the middle of the specimen is calculated as

$f=\Delta-\left(\Delta_{1}+\Delta_{2}\right) / 2$,

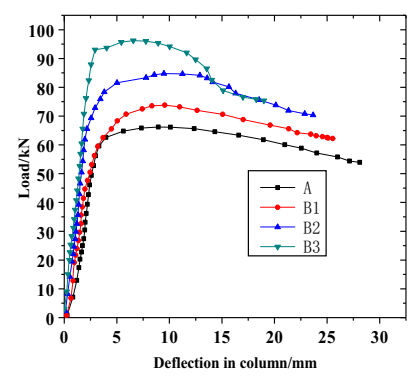

Fig. 11 Load-deflection curves 


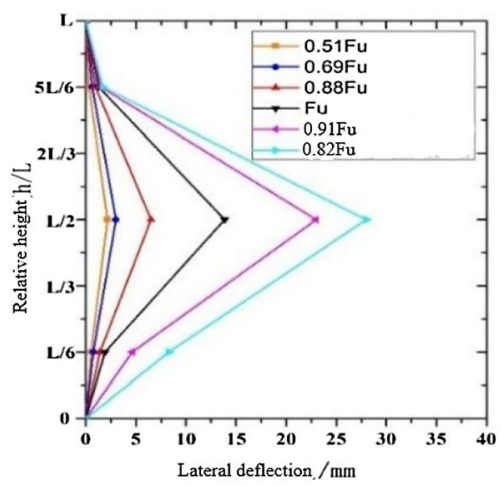

(a) Group-A specimens

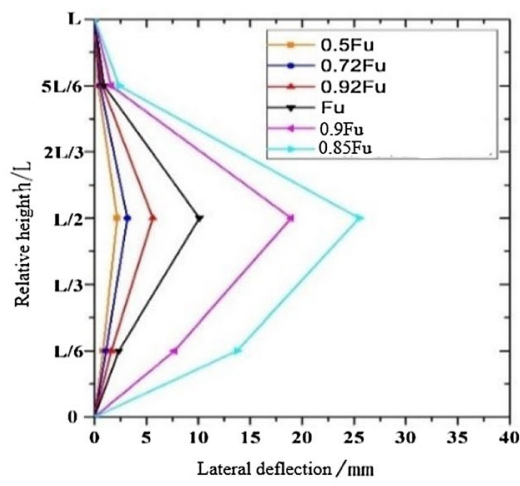

(b) Group-B1 specimens

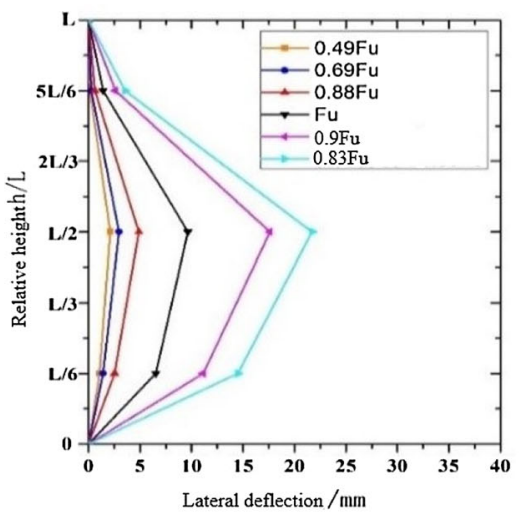

(c) Group-B2 specimens

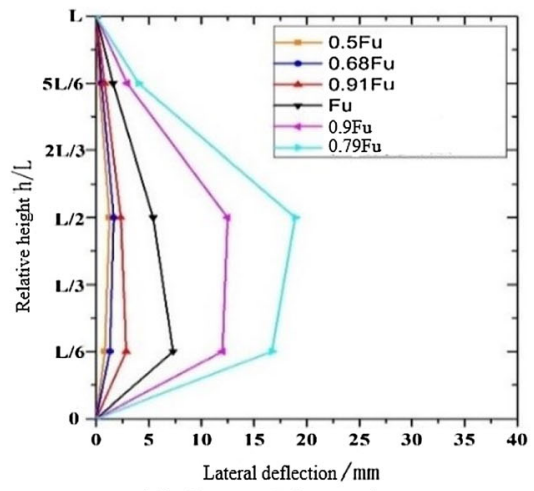

(d) Group-B3 specimens

Fig. 12 Load-lateral displacement curves where $\Delta$ is the displacement at the middle of the specimen, $\Delta_{1}$ is the displacement at $L / 6$ along the specimen, and $\Delta_{2}$ is the displacement at $5 L / 6$ along the specimen.

The overall variation of the load-deflection curve of each specimen is similar, as shown in Fig. 11. In the elastic phase, compared with the unstiffened specimens, the loaddeflection curve shows a linear relationship and the linear slope of the stiffened specimens is larger, that is, the increase speed of the lateral displacement of the stiffened specimens is lower. In the elastic-plastic phase, the average lateral deflections of specimens A, B1, B2, and B3 decrease sequentially. When the critical load is reached, the horizontal section corresponding to the load-deflection curve of the stiffened specimen is shorter, and the lateral deformation of the specimen is not large. After the loading is completed, the ultimate deflection values corresponding to specimens A, B1, B2, and B3 are 28.69, 25.99, 23.15, and $18.72 \mathrm{~mm}$, respectively. Compared with specimen A, the lateral deflection values of stiffened specimens B1, B2, and B3 decreased by 9.4\%, 19.3\%, and $34.7 \%$, respectively.

The load-lateral displacement curve of specimens under different loads are plotted in Fig. 12, where the vertical coordinate is the relative height $(h / L)$ between each measuring point and the bottom of the pier column, and the horizontal coordinate is the lateral deflection of the specimen at different positions during the loading process. It can be seen that during the loading process, the lateral deflection of each section of the specimen increases gradually, and the setting of the SR provides additional lateral constraints for the steel pipe. The lateral deformation of the specimen is constrained effectively, and the wider the SR, the better the lateral constraint effect. The transverse deformation of the unreinforced section of $L / 6$ and $5 L / 6$ of the specimen increases, indicating that the SR (1) strengthens the cooperative working ability between the steel tube and the internal filling material, (2) improves the restraint effect of the steel tube on the internal filling material, (3) delays the buckling deformation of the steel tube in the middle of the specimen, and (4) improves the overall mechanical properties of the specimen.

\subsection{Analysis of load-strain curves}

According to the paste position of strain gauge, take the average strain value at the four sections of $1 / 6$ section, $1 / 3$ section, $1 / 2$ section and $3 / 4$ section respectively to draw the load-strain curves. In the Fig. $13, \varepsilon_{\mathrm{v}}$ is the longitudinal strain and $\varepsilon_{\mathrm{h}}$ is the transverse strain. According to Fig. 13, the curve can be divided into three stages: linear growth, nonlinear increase, and horizontal development. During the loading process, the transverse stress at each section of the 


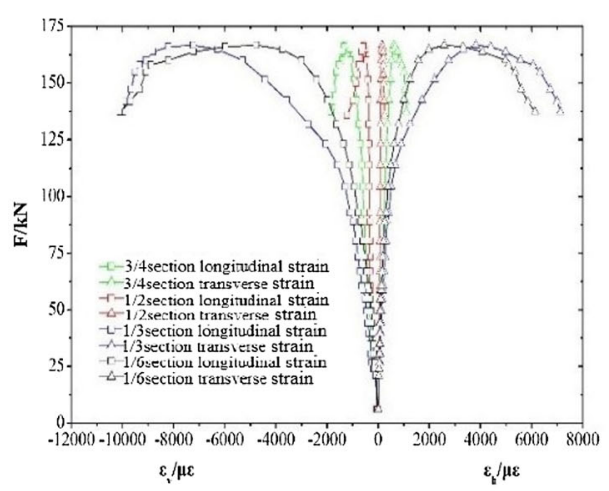

(a) Group-A specimens

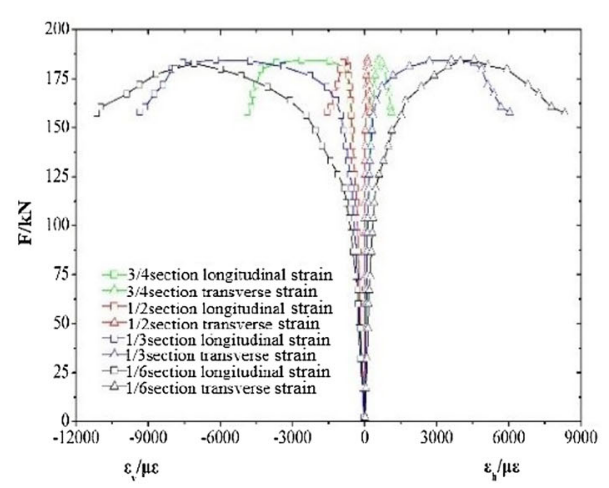

(b) Group-B1 specimens

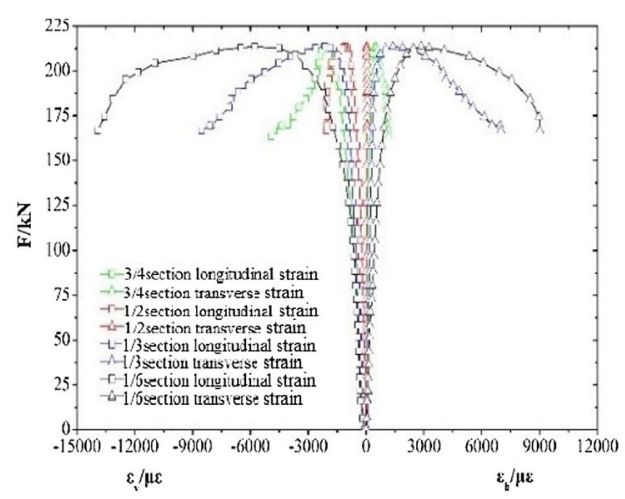

(c) Group-B2 specimens

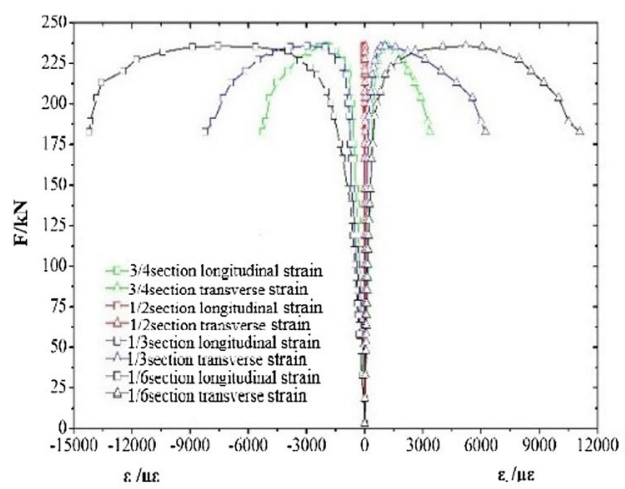

(d) Group-B3 specimens

Fig. 13 Load-strain curves specimen is smaller than the longitudinal stress. The strain values of the $1 / 2$ and $3 / 4$ sections of each specimen are generally small because the steel tube of the upper section does not yield during the loading process, and setting the SR has little influence on the stress distribution of the two sections. The curves of the stiffened specimens bifurcate relatively late compared with those of the unstiffened specimens in the early stage of loading. When the A3 curve bifurcates, the load is $32.5 \mathrm{kN}$; when the load-strain curves of the B1-2, B2-2, and B3-3 specimens bifurcate, the loads are $55,62.5$, and $80 \mathrm{kN}$, respectively. Before the ultimate load is reached, the corresponding strain value of the stiffened specimen is smaller than that of the unstiffened specimen under the same load. After loading, the longitudinal and transverse strain values at the 1/6 section increase with increasing width of the SR, indicating that the existence of the SR gives full play to the material properties of the steel tube. After the SR is set, the longitudinal and transverse strain values are significantly reduced at the $1 / 3$ cross section near the weak point of the pier column. As the width of the SR increases, the corresponding strain value becomes smaller and smaller, which shows that the existence of the SR is effective at improving the bending deformation of the pier-column specimens. The greater the width of the SR, the better the reinforcing effect.

\subsection{Analysis of bearing capacity and ductility}

The bearing capacity and corresponding displacement data of all specimens are listed in Table 6. Bearing capacity is an important reference index for the stiffening design of pier columns. Table 6 shows that the yield bearing capacity and ultimate bearing capacity of the specimens increase significantly after setting the SRs. Compared with the group-A specimens, the yield bearing capacities of the specimens of groups B1-B3 increase by 13\%, 29\%, and $51 \%$, respectively, and the ultimate bearing capacities increase by $10 \%, 29 \%$, and $44 \%$, respectively. When the $\mathrm{SR}$ is $60 \mathrm{~mm}$ wide, the bearing capacity increases the most, which indicates that the larger the contact area between the SR and the steel tube, the stronger the clamp effect of the steel tube on the inner filling material when the specimen enters the elastic-plastic stage under axial pressure, and the better the cooperative working ability between the two, so as to improve the overall bearing capacity of the specimen.

Ductility refers to the capacity of a structure, component, or material to continue to increase its deformation after it has reached yield. It is usually measured by the ductility coefficient, which is the ratio of the maximum displacement $\Delta_{\max }$ of the specimen to the yield displacement $\Delta_{\mathrm{y}}$ (Ross and Etheridge 2000). In practical calculation, $\Delta_{\max }$ generally takes the deformation corresponding to the load falling to $85 \%$ of the ultimate load. According to 
Table 6 List of test data

\begin{tabular}{|c|c|c|c|c|c|c|c|c|}
\hline \multirow{2}{*}{$\begin{array}{l}\text { Specimen } \\
\text { number }\end{array}$} & \multirow{2}{*}{$\begin{array}{l}\text { Width of stiffener } \\
\text { ring }(\mathrm{mm})\end{array}$} & \multicolumn{2}{|c|}{ Yield load point } & \multicolumn{2}{|c|}{ Ultimate load point } & \multicolumn{2}{|c|}{ Maximum displacement point } & \multirow[t]{2}{*}{$\overline{\mu_{\Delta}(\mathrm{mm})}$} \\
\hline & & $F_{\mathrm{y}}(\mathrm{kN})$ & $\Delta_{\mathrm{y}}(\mathrm{mm})$ & $F_{\mathrm{u}}(\mathrm{kN})$ & $\Delta_{\mathrm{u}}(\mathrm{mm})$ & $F_{0.85 \mathrm{u}}(\mathrm{kN})$ & $\Delta_{\max }(\mathrm{mm})$ & \\
\hline A1 & - & 132.05 & 25.02 & 163.00 & 30.71 & 138.70 & 40.66 & 1.63 \\
\hline $\mathrm{A} 2$ & - & 125.83 & 24.85 & 166.70 & 30.93 & 142.15 & 41 & 1.65 \\
\hline A3 & - & 121.35 & 24.75 & 165.55 & 30.04 & 140.73 & 42.37 & 1.71 \\
\hline B1-1 & 40 & 148.53 & 26.71 & 184.78 & 34.26 & 157.05 & 47.99 & 1.80 \\
\hline B1-2 & 40 & 139.90 & 26.2 & 184.48 & 33.71 & 156.80 & 47.09 & 1.80 \\
\hline B1-3 & 40 & 140.65 & 27.22 & 177.73 & 34.85 & 151.08 & 47.6 & 1.75 \\
\hline B2-1 & 50 & 168.43 & 28.45 & 214.58 & 39.01 & 182.40 & 52.01 & 1.83 \\
\hline B2-2 & 50 & 162.70 & 28.58 & 211.85 & 39.67 & 180.08 & 51.59 & 1.81 \\
\hline B2-3 & 50 & 158.23 & 29.92 & 213.58 & 40.1 & 181.55 & 53.86 & 1.80 \\
\hline B3-1 & 60 & 190.15 & 29.82 & 240.58 & 43.95 & 204.50 & 56.92 & 1.91 \\
\hline B3-2 & 60 & 189.13 & 31.08 & 238.45 & 46.64 & 202.68 & 55.9 & 1.80 \\
\hline B3-3 & 60 & 193.53 & 31.15 & 235.73 & 47.7 & 200.38 & 57.99 & 1.86 \\
\hline
\end{tabular}

Notes $\Delta_{\mathrm{y}}$ is yield displacement; $F_{\mathrm{y}}$ is yield bearing capacity; $\Delta_{\mathrm{u}}$ is ultimate displacement; $F_{\mathrm{u}}$ is ultimate bearing capacity; $\Delta_{\max }$ is maximum displacement; $F_{0.85 u}$ is bearing capacity corresponding to maximum displacement point, which refers to longitudinal displacement point corresponding to bearing capacity falling to $0.85 F_{\mathrm{u}}: \mu_{\Delta}$ is ductility coefficient

existing research, the yield point is determined and the corresponding yield displacement $\Delta_{\mathrm{y}}$ is found by geometric drawing method on load displacement curve (Zha et al. 2012).

From the increase coefficient of the yield load and the yield displacement of the specimens in Table 6, it can be concluded that the ductility of the specimen is increased by $7 \%, 9 \%$, and $12 \%$ when the SR width is 40,50 , and $60 \mathrm{~mm}$, respectively. This shows that the existence of the SR improves the ductility of the specimen, but only because in the loading process the diameter of the steel pipe in the lower section gradually becomes thicker under the expansion and extrusion of the internal filler material. When the gap between the upper and lower steel pipes is filled, the two steel pipes and the SR can be regarded as a whole, and the restraining area of the SR is smaller than the total cross-sectional area of the steel-pipe cross section, and the change of SR width has little effect on the proportion of the area of the restraint. So as the width of the SR changes, the increase in ductility is not significant.

\section{Finite-element analysis}

\subsection{Establishment and verification of finite-element model}

\subsubsection{Establishment of finite-element model}

An FE model of the pier-column specimen is established. The steel is subjected to an ideal elastic-plastic reinforced model. The composition and properties of the filler in piercolumn studies are similar to those of concrete. Based on research into the constitutive relation of concrete (Niu 2012), the Drucker-Prager yield criterion is adopted for the failure criterion (Liu 2017). The parameters of the filling materials for pier column are derived from those of sand and gravel filling in geotechnical engineering (Wang et al. 2015). The specific physical and mechanical parameters are given in Table 7.

An eight-node linear reduced integral solid element (C3D8R) is used for the pier-column model elements. To ensure convergence, an end plate is defined as an elastic rigid body at both ends of the pier column. The elastic modulus of the end plate is increased to $E=20^{6} \mathrm{MPa}$, and the Poisson's ratio is 0.0001 , and the constraint between the end plate and the pier-column interface is a binding constraint. Reference points are fitted near the upper and

Table 7 Model physical and mechanical parameters

\begin{tabular}{ll}
\hline Parameter & Value \\
\hline Elastic modulus of steel (MPa) & $2.06 \times 10^{11}$ \\
Poisson's ratio & 0.30 \\
Poisson's ratio of filler & 0.22 \\
Elastic modulus of filler $(\mathrm{MPa})$ & $2.80 \times 10^{4}$ \\
Density $\rho$ of filler $\left(\mathrm{kg} / \mathrm{m}^{3}\right)$ & 2000 \\
Internal friction angle $\beta$ of filler $\left(^{\circ}\right)$ & 30 \\
Expansion angle $\psi$ of filler $\left(^{\circ}\right)$ & 5 \\
Ratio $K$ of triaxial tensile strength & 0.778 \\
$\quad$ to compressive strength & \\
\hline
\end{tabular}




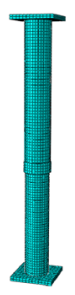

Fig. 14 Schematic of finite-element (FE) model

lower end plates and are coupled with each other. The contact relationship between the steel pipe and its internal filler is surface-to-surface contact. Hard contact is used to simulate the normal contact behavior. The inner surface of the steel tube is the main control surface, and the outer surface of the inner filling material is the subordinate surface. The contact surfaces of the two sections of steel pipes are surface-to-surface contact, the tangential friction coefficient is 0.1 , and there is hard contact in the normal direction. The restraint between the SR and the steel pipe is a binding restraint.

The FE analysis model based on the above method is shown in Fig. 14. According to the boundary condition that all loading ends are articulated, the top of the model is selected as the loading end, and the load and boundary conditions of the model are applied to the end plate. The displacements $\mathrm{U} 1$ and $\mathrm{U} 2$ and the rotation angles UR1 and UR3 of the upper end plate are constrained, and the displacement is allowed to develop along the direction of U3, namely the $z$ axis, with the load. Displacement control is applied to U3 of the upper end plate to simulate the axial compression loading.

\subsubsection{Validation of finite-element model}

Figure 15 shows the failure modes of axially compressed specimens calculated by the FE method. It can be seen that all the failure modes are local bending failure. The lateral deflection of the stiffener specimen decreases significantly, and the local buckling amplitude of the lower section steel tube weakens. The existence of SRs is effective at reducing the buckling of the steel tube wall and limiting the overall lateral displacement of the pier-column specimens. Also, the numerically calculated failure mode is consistent with that of the axial compression test.

The stress nephograms of the unstiffened specimen, a stiffened specimen, and the internal filler are shown in Fig. 16. These show that the coverage area of the ultimate stress of the steel tube and internal filler decreases gradually with the increase of the width of the SR, and the distribution of axial compressive stress of the steel tube and internal filler is more uniform.

The load-displacement curves calculated by the FE method are shown in Fig. 17. The curves are smooth and

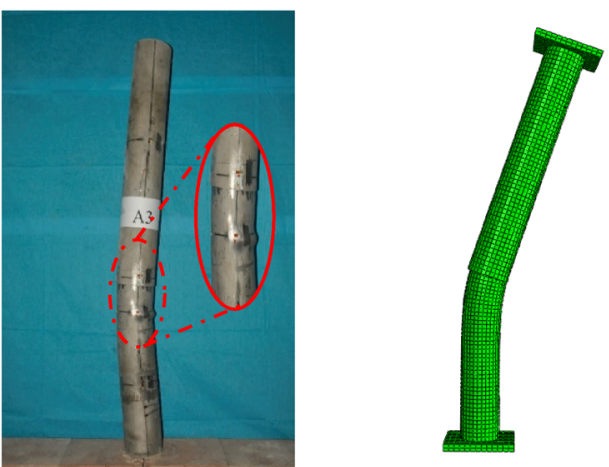

(a) Unstiffened specimen A3

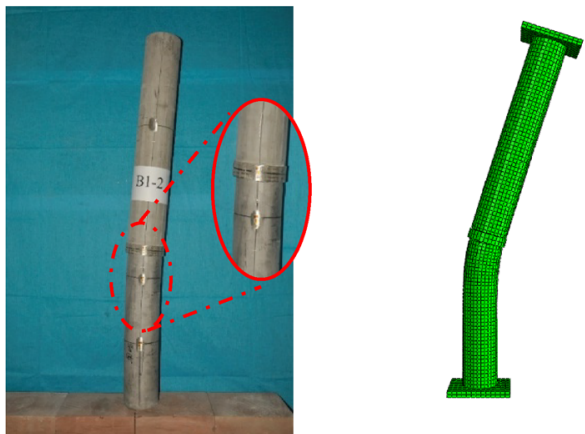

(b) Stiffened 40-mm specimen B1-2
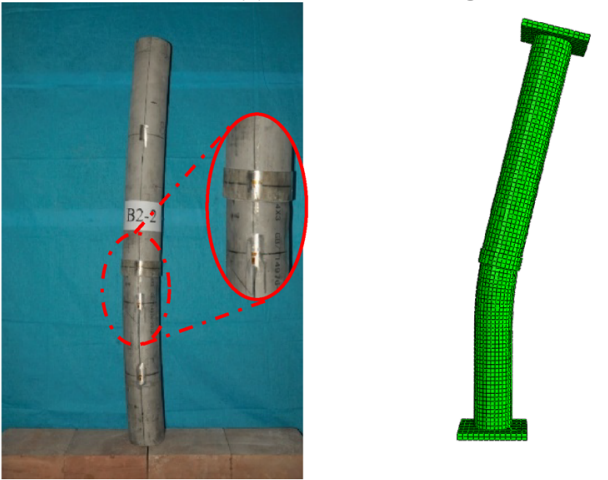

(c) Stiffened 50-mm specimen B2-2
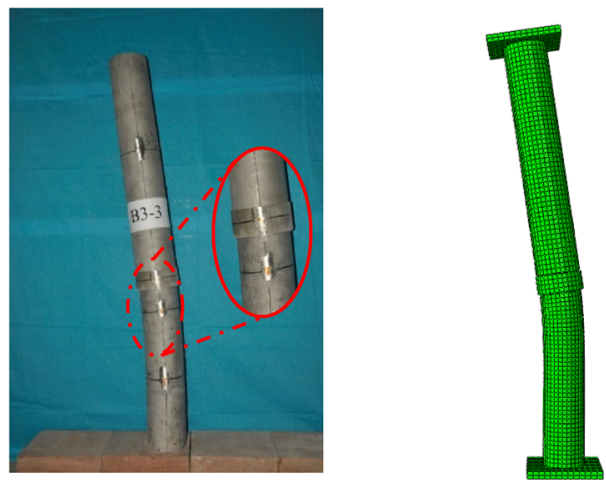

(d) Stiffened 60-mm specimen B3-3

Fig. 15 Comparison of failure modes under axial compression

above but consistent with the experimental curves obtained by the axial compression test. Generally speaking, the results of the FE calculation agree with the experimental results. 


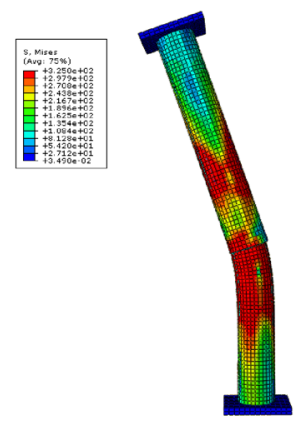

(a) Steel tube (unstiffened)

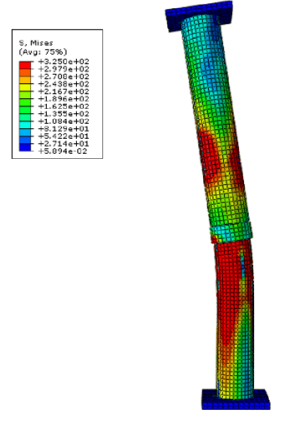

(b) Steel tube (60-mm stiffener)

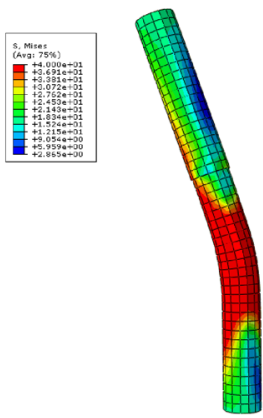

(c) Filling material (unstiffened)

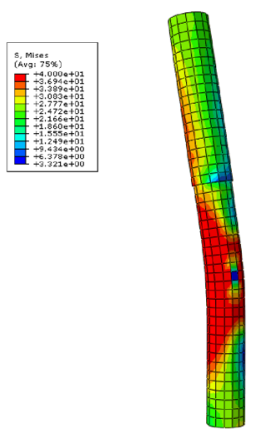

(d) Filling material (60-mm stiffener)

Fig. 16 Comparison of nephograms of axial compressive stress

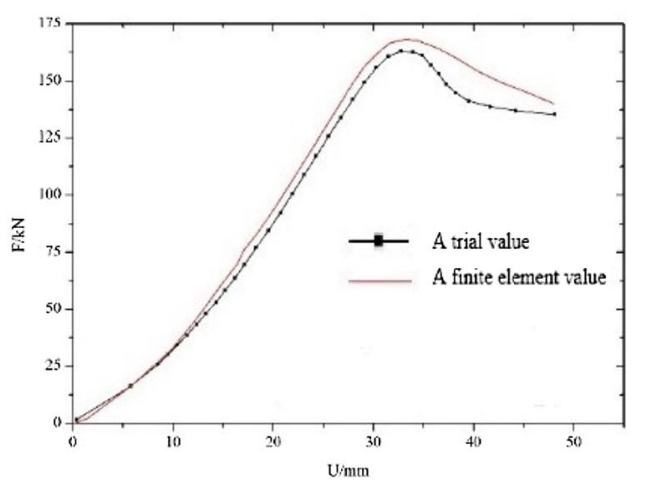

(a) Unstiffened specimen

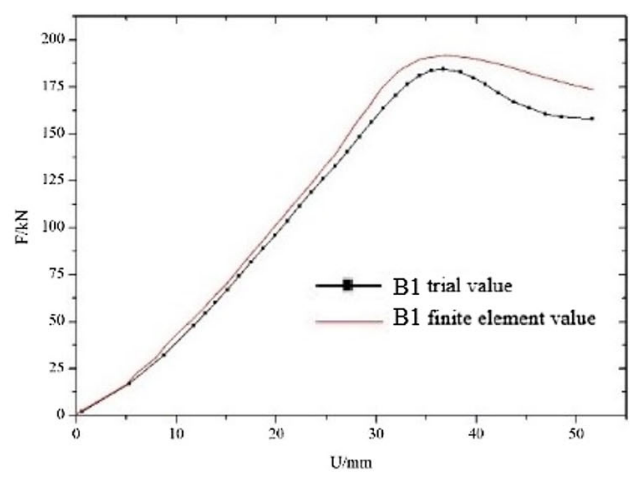

(b) Specimen with 40-mm-wide SR

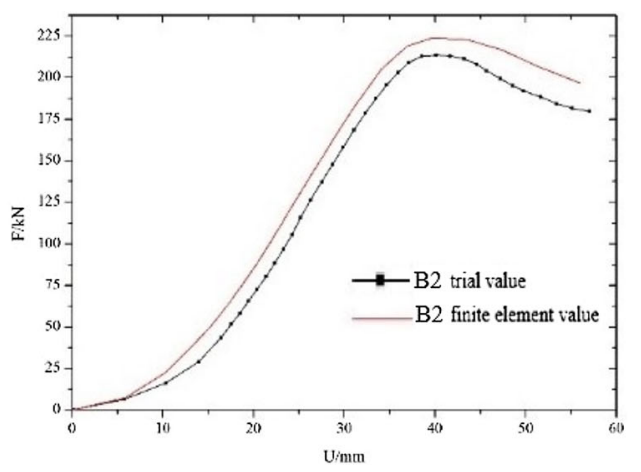

(c) Specimen with 50-mm-wide SR

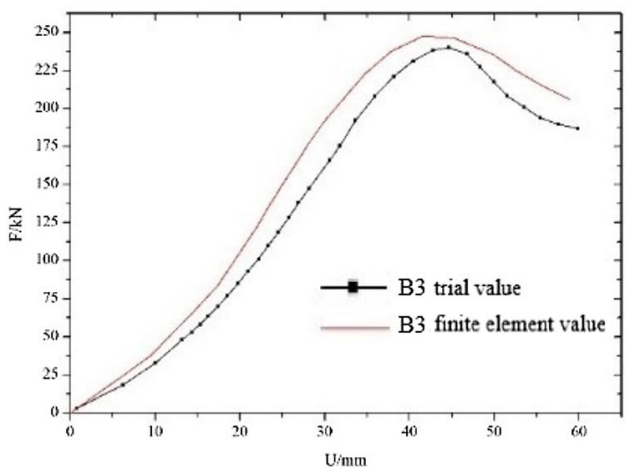

(d) Specimen with 60-mm-wide SR

Fig. 17 Comparison of load-strain curves 


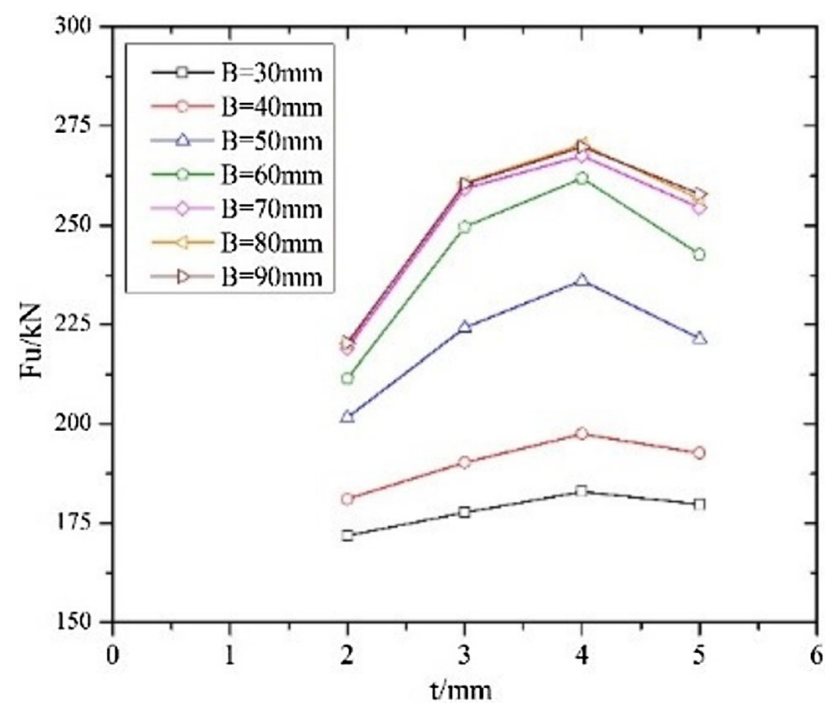

Fig. 18 Curves of $F_{\mathrm{u}}-t$ relationship

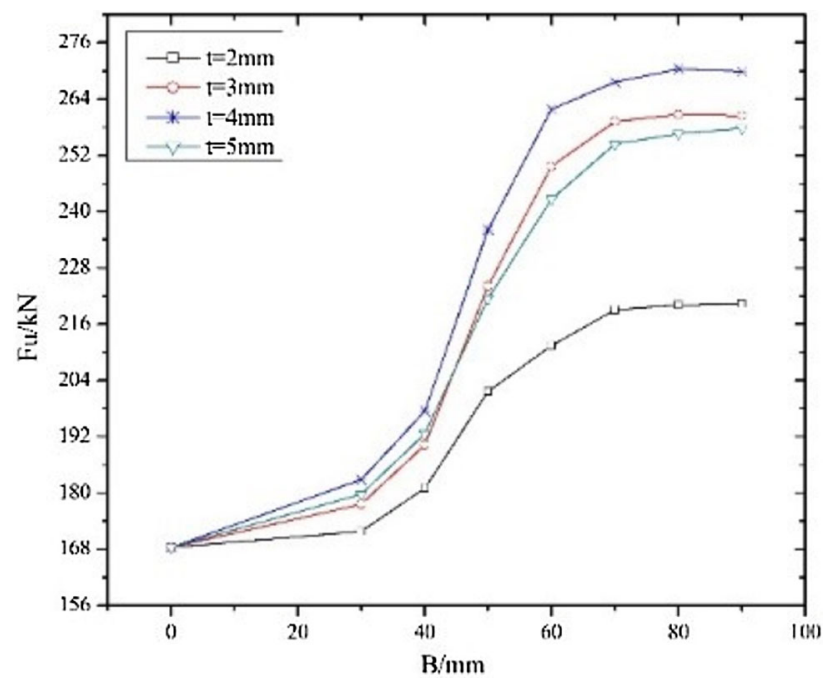

Fig. 19 Curves of $F_{\mathrm{u}}-B$ relationship

\subsection{Analysis of finite-element results}

The above FE model is used to perform numerical simulations of SRs whose width is either less than $40 \mathrm{~mm}$ or more than $60 \mathrm{~mm}$, for which no experimental studies were performed. The thickness changes of the SRs are determined to be 2, 3, 4, and 5, and the widths of the SR are 30, $40,50,60,70$, and $80 \mathrm{~mm}$.

The relationship between the thickness $t$ of the SR and the ultimate bearing capacity is plotted in Fig. 18, and the relationship between the width $B$ of the SR and the ultimate bearing capacity is plotted in Fig. 19. From Fig. 18, the variation of the ultimate bearing capacity of the pier column is small for $B \leq 40 \mathrm{~mm}$. For $B>40 \mathrm{~mm}$, the $F_{\mathrm{u}^{-}}$ $t$ curve shows a trend of rapid rise initially, then slow rise,

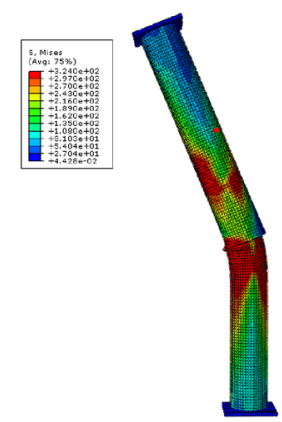

(a) Prototype pier-column steel tube

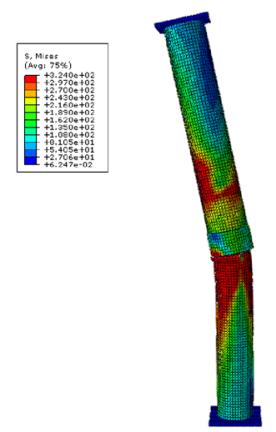

(b) Steel pipe for stiffened pier column

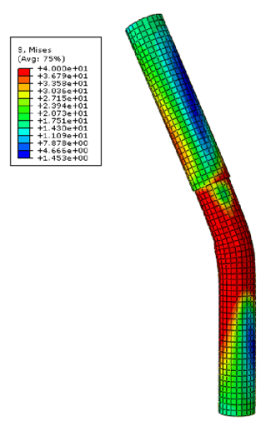

(c) Filling material (prototype)

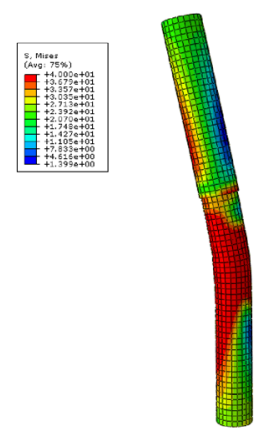

(d) Filling material (stiffened pier column)

Fig. 20 Comparison of FE stress nephograms

and finally decline. The curve has its maximum at $t=4 \mathrm{~mm}$, and the ultimate bearing capacity of the pier 


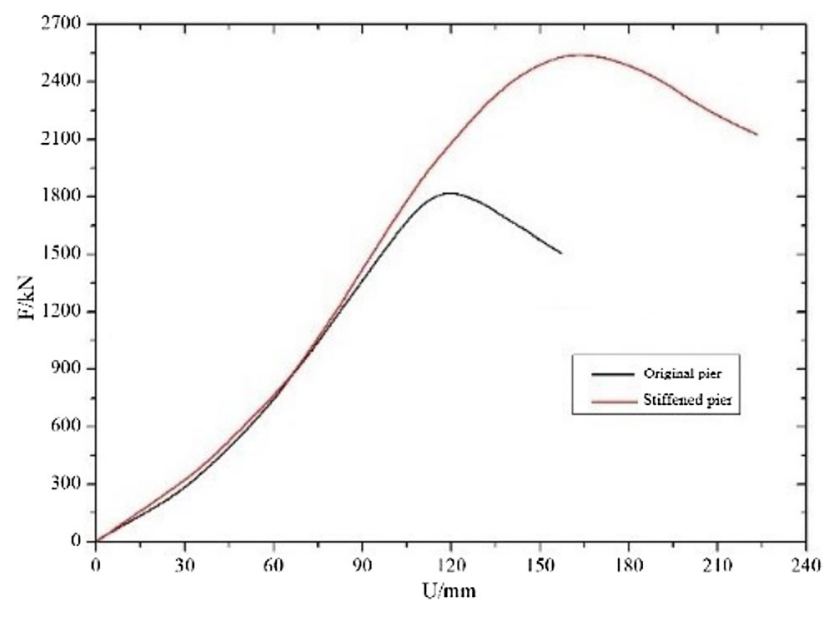

Fig. 21 Comparison of FE load-displacement curves

column strengthened with an SR of various width reaches the maximum value. The reasons for the above trend are as follows. When the width of the SR is small, its lateral restraint force on the pier column is equal to the effect of stirrups on the pier column, the thickness of the SR is equal to the diameter of the stirrups, and a single stirrup has less influence on the pier column as a whole. When the width of the SR is larger than $40 \mathrm{~mm}$, the contact area between the SR and the steel tube increases, which is equivalent to the joint work of several stirrups. The transverse restraint effect provided to the steel tube is strengthened. When the thickness of the SR exceeds $4 \mathrm{~mm}$, the ultimate bearing capacity of the pier decreases, and the thickness of the SR is too large, resulting in its strong effect on the hoop of the steel pipe. When the gap reserved at the lap joint is filled, the transverse deformation of the lower section of steel pipe at the bottom of the lap joint exceeds the transverse deformation of the upper section of the steel pipe, where the steel pipe will yield in advance.

As shown in Fig. 19, when $B \leq 40 \mathrm{~mm}$, the bearing capacity of the pier column does not change much with the width of the SR. When $40 \mathrm{~mm}<B<70 \mathrm{~mm}$, the ultimate bearing capacity of the pier column increases with the increase of the width of the SR. When $B>70 \mathrm{~mm}$, changing the SR width has little effect on the ultimate bearing capacity of the pier column. When the width of the SR is small, the contact area with the steel pipe is small, which has little effect on the bearing capacity of the pier column. When the width of the SR is too large, the contact area with the steel tube increases, but there are redundant areas that are not involved in the work. Only when the width of the SR is appropriate can the cooperative working ability between the steel pipe and the filling material be improved through transverse restraint, and the full section of the SR be guaranteed to work, causing the bearing capacity of the pier column to reach its optimum value.
According to the curve, the optimal width of the SR is $70 \mathrm{~mm}$.

The optimal size of the SR is determined by FE software as being $B=70 \mathrm{~mm}, t=4 \mathrm{~mm}$, and the ultimate bearing capacity of the specimens is $267.55 \mathrm{kN}$, which is about $592 \%$ higher than that of unstiffened specimens. Based on this result, the optimum stiffening dimensions of solid pier columns for roadside support in the Wutongzhuang Mine in Hebei Province are determined as $B^{\prime}=200 \mathrm{~mm}, t^{\prime}=10$ $\mathrm{mm}$. The bearing capacity of the prototype pier column after stiffening is verified. Figure 20 compares the stress nephograms before and after stiffening. The comparison results of the FE load-displacement curves are shown in Fig. 21. According to Fig. 21, the ultimate bearing capacity of the prototype pier column is $1645.11 \mathrm{kN}$, the ultimate bearing capacity of the stiffened pier column is $2609.25 \mathrm{kN}$, and the increase of bearing capacity after stiffening is $58.61 \%$. It is proved that the effect of stiffening is better.

\section{Conclusions}

(1) Additional transverse constraints are effective for stiffening the pipe wall and enhancing the cooperative working ability between the steel pipe and the internal filling material, thereby improving the bearing capacity of the pier-column specimens.

(2) Setting an SR is effective for improving the yield bearing capacity and ultimate bearing capacity of the pier-column specimens.

(3) The presence of the SR is effective for restricting the lateral deformation of the pier-column specimens. As the width of the SR increases, the transverse restraint effect is better, the deflection value of the pier column decreases, and the overall stability of the pier column is higher.

(4) Setting an SR improves the ductility of the specimens to some extent, but their ductility is insensitive to changing the width of the SR because the constraint area of the SR is small relative to the total section area of the specimens.

(5) The ultimate bearing capacity of the pier column is related to the width and thickness of the SR. The optimal stiffening dimensions of the model pier column are determined as a width of $70 \mathrm{~mm}$ and a thickness of $4 \mathrm{~mm}$, the choice of which increases the ultimate bearing capacity of the pier column by $58.61 \%$.

Open Access This article is licensed under a Creative Commons Attribution 4.0 International License, which permits use, sharing, adaptation, distribution and reproduction in any medium or format, as 
long as you give appropriate credit to the original author(s) and the source, provide a link to the Creative Commons licence, and indicate if changes were made. The images or other third party material in this article are included in the article's Creative Commons licence, unless indicated otherwise in a credit line to the material. If material is not included in the article's Creative Commons licence and your intended use is not permitted by statutory regulation or exceeds the permitted use, you will need to obtain permission directly from the copyright holder. To view a copy of this licence, visit http://creativecommons. org/licenses/by/4.0/.

\section{References}

Dong JF, Wang QY, Guan ZW (2013) Structural behavior of recycled aggregate concrete filled steel tube columns strengthened by CFRP. Eng Struct 48(Complete):532-542

Ganesh PG, Sundarraja MC (2013) Behavior of concrete filled steel tubular (CFST) short columns externally reinforced using CFRP strips composite. Constr Build Materials 47(2):1362-1371

GB 50017-2003 (2003) Steel structure design code

Guo LH, Niu B, Yang SJ (2013a) Study on thin-walled circular hollow sections with and without stiffeners subjected to bending. China Civ Eng J 8:19-27

Guo LH, Niu B, Yang SJ (2013b) Study on thin-walled circular hollow sections with and without stiffeners subjected to bending. J Civ Eng 8:19-27

Guo DM, Fan LF, Gao J (2018) Study on sidewall support technology of pier pillar type gateway retained along goaf in Wutongzhuang Mine. Coal Sci Technol 46(01):81-87

Hassanein MF, Kharoob OF, Liang QQ (2013) Circular concretefilled double skin tubular short columns with external stainless steel tubes under axial compression. Thin Walled Struct 73(79):252-263

He MC, Chen SY, Guo ZB (2017) Control of surrounding rock structure for gob-side entry retaining by cutting roof to release pressure and its engineering application. J China Univ Min Technol 5:959-969
Jack AS, Hamed LR, Chengguo Z, Wendy T (2019) Analysis of the influence of groundwater and the stress regime on bolt behaviour in underground coal mines. Int J Coal Sci Technol 6(2):286-300

Jia M, Bai JB, Tian T (2014) Research on pier column gob-side entry retaining technology. Coal Sci Technol 42(1):18-22

Ju Y, Zhu Y, Xie HP, Nie XD, Zhang Y et al (2019) Fluidized mining and in situ transformation of deep underground coal resources: a novel approach to ensuring safe, environmentally friendly, lowcarbon, and clean utilisation. Int $\mathrm{J}$ Coal Sci Technol 6(2):184-196

Li W, Han LH, Zhao XL (2012) Axial strength of concrete-filled double skin steel tubular (CFDST) columns with preload on steel tubes. Thin Walled Struct 56(4):9-20

Li S, Li JW, Han YL (2015) Study on support resistance of roadway along goaf in fully mechanized top coal caving face. J Saf Environ 15(1):133-136

Liu XO (2017) Experimental study on optimization of filling material ratio of compressible pier. Master's Thesis

Niu B (2012) Analysis of thin-walled circular stiffened steel tubes subjected to bending. Harbin Institute of Technology, Harbin

Park JW, Choi SM (2013) Structural behavior of CFRP strengthened concrete-filled steel tubes columns under axial compression loads. Steel Compos Struct 14(5):453-472

Qian MG, Xu JL, Miu XX (2003) Green technique in coal mining. J China Univ Min Technol 04:5-10

Ross CTF, Etheridge J (2000) The buckling and vibration of tubestiffened axisymmetric shells under external hydrostatic pressure. Ocean Eng 27(12):1373-1390

Wang J, Gao YF, He XS (2015) The analysis of roadside supporting parameters and the support technology in the concrete filled steel tubular column in goaf-side entry retaining. J Min Saf Eng 32(06):943-949

Xiao Y, He WH (2003) Development of confined CFST columns. J Harbin Inst Technol 35(s1):40-42

Zha XX, Li WQ, Yu M (2012) Seismic behavior study of hollow ordinary concrete and recycled aggregate concrete filled steel tubular (CFST) columns I: theoretical study. Progr Steel Build Struct 14(3):36-41 